This is an Accepted Manuscript of an article published by Taylor \& Francis in "Materials and manufacturing processes" on 2020, vol. 35, núm. 2, p. 123-129, available online:

https://www.tandfonline.com/doi/abs/10.1080/10426914.2019.1628268 


\title{
Surface Patterning of Cemented Carbides by Means of Nanosecond
}

\section{Laser}

\author{
Shiqi Fang ${ }^{\mathrm{a}, \mathrm{b}}$, Víctor Pérez Rustarazo ${ }^{\mathrm{a}}$, Nuria Salán ${ }^{\mathrm{a}}$, Dirk Bähre ${ }^{\mathrm{b}}$ and \\ Luis Llanes ${ }^{\mathrm{a}, *}$
}

${ }^{a}$ CIEFMA - Dept. Materials Science and Metallurgical Engineering, EEBE - Campus

Diagonal Besòs, Universitat Politècnica de Catalunya, Barcelona, Spain; ${ }^{b}$ Institute of

Production Engineering, Saarland University, Saarbrücken, Germany

*Corresponding author email: luis.miguel.1lanes@upc.edu

\begin{abstract}
A nanosecond laser combined with a 2-axis reflection control unit is used to shape polygonal pyramids with defined geometry on a specific cemented carbide grade. In total, 12 different surface patterns have been fabricated, including four pyramid shapes, i.e. triangle, square, hexagon and octagon, and three lateral side angles, i.e. $30^{\circ}, 45^{\circ}$ and $60^{\circ}$. Characterization of the geometrical features shows satisfactory agreement between produced patterns and aimed ones. The precision is improved when the number of polygon sides and/or both side and slope angles increase. Side effects, such as re-deposition, cracks and pores, were discerned through scanning electron microscopy inspection. They become less obvious when the polygon side length or side angle increases, as the material melting becomes less important. Based on the observations, a borderline curve can be plotted for describing the production capability of such surface patterns on cemented carbides using the laser technology.
\end{abstract}

Keywords: cemented, carbides, laser, texturing, abrasive, machining, processes, surface, integrity

\section{Introduction}

Abrasive machining, such as grinding, honing and lapping, can be described as 
removal of material by the action of multitude of small hard particles, usually embedded in soft binders [1-3]. It takes place as the sharp edges of these grains - protruding out of the cutting surface - penetrate into the material, due to the pressing force, and shear it as a result of the sliding movement between tool and workpiece. In general, abrasive machining yields higher precision and better tolerance than other surface finishing processes, being the main reason for their extensive implementation in industry. On the other hand, it is considered as an expensive process, and high cost of tool materials is one important intrinsic factor. Hence, increasing cost-effectiveness of abrasive tool materials is a clear industrial need.

Advanced abrasive tools are usually made from sintered composite materials which mainly consist of hard abrasive grains, such as cubic boron nitride $(\mathrm{CBN})$ or diamond, and a binder either metallic or resin [4]. However, geometrical arrangement (distribution) and features (mainly shape and orientation) of these grains are not homogeneous and this heterogeneity nature can cause instabilities in the cutting process or even tool failures [1,5-7]. Therefore, achievement of a more homogeneous distribution and precise geometry of abrasive grains has become a relevant demand. On the other hand, it is pointed out that defined geometrical features of tool surfaces can achieve better tribological properties and improve cutting stability $[8,9]$.

Recently, the authors of this study have successfully sculptured hexagonal pyramids with defined geometry, similar to $\mathrm{CBN}$ abrasive particles, on a cemented carbide grade by using an ultra-short pulse laser [10,11]. Compared to a CBN honing stone, these pyramids achieved similar effectiveness in material removal, as assessed in preliminary abrasive machining tests. Within this framework, this investigation aims to produce different functionally-driven patterns on a cemented carbide grade by changing geometry of pyramid-like repetitive units. In particular, features with triangle, square, 
hexagon and octagon shapes and different dimensions will be attempted using a nanosecond laser. In doing so, effort will be devoted to prove the feasibility of the laser treatment by evaluating precision implicit to the production of such complex geometrical features as well as to assess surface integrity of the shaped cemented carbide.

\section{Experimental aspects}

\subsection{Materials}

The material used is a commercial WC-Co cemented carbide (also known as hardmetal), supplied by Hyperion Materials \& Technologies and referred to as 10CoC in this study. It is a relatively coarse grade (mean carbide size of $2.3 \square \mathrm{m}$ ) containing a binder amount of $10 \mathrm{wt} . \%$. A scanning electron microscopy (SEM) image, representative of the microstructure, is given in Figure 1(a). This hardmetal grade exhibited a Vickers hardness of 11.4 GPa and a fracture toughness of $15.8 \mathrm{MPa} \sqrt{\mathrm{m}}$ [12].

\subsection{Design of surface patterning}

In previous work by the authors [8,9], geometrical features of the abrasive grains exposed on the cutting surfaces of two commercial honing stones with middle/large grain size and density have been characterized in terms of quantity, dimension, shape and position. The statistical investigation of grain shape reveals that most of the grains, i.e. about $80 \%$ or higher, have a shape of polygons (rectangle-octagon-circle) shown in Figure 1(b,c). The shape features of abrasive grains participating in the cutting processes can be described by defining their cutting edges [13]. The cutting edge (Figure 1(d)) is the sharp side of the grain penetrating into the counterpart and determines principally the material removal effectiveness [14]. Therefore, definition and 
shaping of pyramid slopes provides the possibility to determine the dimensional parameters of the cutting edges.

In this study, four typical shapes (Figure 2) have been specifically targeted based on the previous characterization results: triangle (for the minor case), square, hexagon and octagon (for the major case), and with sizes complying with honing stones of middle to large grain size, i.e. $100 \mu \mathrm{m}$ to $200 \mu \mathrm{m}[6,7]$. Each shape includes three profiles with variable side angles of $30^{\circ}, 45^{\circ}$, and $60^{\circ}$ (i.e. a total of 12 different patterns as shown in Table 1).

\subsection{Surface modification using nanosecond laser}

\subsubsection{Selection of laser machining parameters on geometrical precision}

From the technical point of view, overlap and fluence are the most important operating parameters in practice, regarding direct impact on the surface quality of the workpieces. The overlap (Equation 1) is a dimensionless parameter describing the superposition of two adjacent dimples produced by laser pulses (Figure 3(a)) [15]:

$$
\begin{aligned}
& U=1-\frac{v}{f_{z} \cdot D} \\
& U \text { : overlap in percentage } \\
& v \text { : scan speed }(\mathrm{mm} / \mathrm{s}) \\
& D \text { : spot size }(\mu \mathrm{m}) \\
& f_{z} \text { : pulse repetition frequency }(\mathrm{Hz})
\end{aligned}
$$

In general, when the scan speed decreases, the overlap increases. The depths of ablated tracks increase with the overlap, and the widths exhibit similar tendency as long as the overlap is larger than $50 \%$. A slow scan speed, i.e. large overlap, affects negatively the production efficiency and the finished surface roughness. On the other hand, a fast scan speed, i.e. small overlap, may cause discontinuity on the ablated tracks, such as residual peaks. It is reported that the optimal range of overlaps is between $30 \%$ to $60 \%$ [15]. The spot size should theoretically be equal to the diameter of 
the focus point, calculated using the following equation $[16,17]$ :

$d_{f}=\frac{4 \lambda}{\pi} \frac{M^{2} f}{d_{L}}$

$\lambda$ : wavelength (nm)

$M^{2}$ beam quality factor

$f$ : focal length $(\mathrm{mm})$

$d_{L}$ : beam with $(\mathrm{mm})$

Laser fluence describes the pulse energy delivered per unit (or effective) area. i.e. the ratio between the pulse energy and effective spot area, given by the following equation $[16,17]$ :

$F=\frac{E_{o}}{A}=\frac{86.5 \% \cdot E_{p}}{A}$

$F$ : fluence $\left(\mathrm{J} / \mathrm{cm}^{2}\right)$

$E p$ : pulse energy $(\mu \mathrm{J})$

Eo: effective pulse energy $(\mu \mathrm{J})$

$A$ : spot area $\left(\mathrm{cm}^{2}\right)$

The effective pulse energy is usually calculated at the position $1 / \mathrm{e}^{2}$ of the laser beam with Gaussian form profile (TEM00), corresponding to $86.5 \%$ of the pulse energy. It is reported that the fluence of around $2.5 \mathrm{~J} / \mathrm{cm}^{2}$ is suitable to selectively ablate the cobalt binder by a Q-switch nanosecond laser. Meanwhile, a complete ablation of cemented carbide could be achieved when the fluence increases to $10 \sim 20 \mathrm{~J} / \mathrm{cm}^{2}[18]$. Machining time can be reduced using high fluence; however, it can also lead to rough surface if the fluence overpasses certain value.

\subsubsection{Laser configuration and determination of machining parameters}

In this study, a nanosecond Q-switched laser unit (Nd:YLF, Explorer® One ${ }^{\mathrm{TM}}$ Spectra Physics) is employed to sculpture pyramids. The laser unit is composed of a laser source, two deflecting mirrors, a deflection unit and a working stage (Figure 3(b)). The laser beam is emitted from the laser source, and then consequently deflected. Within those units, the laser beam is focused and adjusted to specific projecting position (working point) on the XY-plan. The counterpart (sample) is fixed on the sample 
holder, equipped with Vernier callipers along the x-, y- and z- axis. During the laser treatment, the applied laser beam scans the surface of the cemented carbide grade along the $\mathrm{x}$ - axis with a line-by-line mode (Figure 3(c)). The laser beam moves from the left side to the right one of the sample surface, and then jumps to the next line. The emission switch of the laser beam is synchronously controlled by the deflection unit. When the laser beam passes through the pyramid, the emission is suspended to leave the material intact. Therefore, the shape of the pyramids is sculptured by the moving laser beams. With the laser parameters shown in Table 2, 12 scan repetitions are then applied on the sample surface to sculpture the 3D pyramids by ablating a total thickness of $25 \mu \mathrm{m}$, i.e. each scan of the laser beam removes a thickness of about $2.1 \mu \mathrm{m}$.

\section{Results and discussion}

\subsection{Evaluation of geometrical precision}

The geometrical precision of the laser-produced pyramids was evaluated by laser scanning microscopy (LSM). All measured geometrical parameters are shown in Figure 2 and a measurement example of the produced hexagonal pyramid is illustrated in Figure 3(d). Reconstructed 3D models of the pyramids with the four shapes are shown in Figure 4(a-d). At the bottom position, a wave profile can be clearly discerned. It is the residual trace of the laser beam with the interval about $30 \mu \mathrm{m}$, corresponding to the overlap of $43 \%$, i.e. $8.4 \mu \mathrm{m}$ between two laser beams with the width of $19.6 \mu \mathrm{m}$. The depth of the wave profile is about $2 \mu \mathrm{m}$, corresponding to the aforementioned ablation depth of one single pulse. The laser induced wave profiles form dimple-like structures from both horizontal and vertical directions. These structures might be beneficial in the cutting processes, as they can serve as supplementary lubricant 
reservoirs and improve tribological performances [19,20].

Nine measurements were carried out for each specific pyramid shape. Experimentally measured data are given in Table 1 and compared with aimed ones in Figure 5. A quite satisfactory agreement is found for most of the measured geometrical parameters: height, side lengths and slope angles. As it is evidenced in Figure 5a, except the cases $3(\mathrm{~T}) 30^{\circ}, 3(\mathrm{~T}) 45^{\circ}$, and $4(\mathrm{~S}) 30^{\circ}$, most of the produced pyramids achieved the designed height and the side length at the bottom with only slight deviations (less than $1 \mu \mathrm{m}$ and $2 \mu \mathrm{m}$, respectively). Deviations higher than $3 \mu \mathrm{m}$ is found at the top side length of $4(\mathrm{~S}) 45^{\circ}$ and $6(\mathrm{H}) 60^{\circ}$ (Figure 5(c)). This might be caused by uncertainty in determining the position of the pyramid edge under the microscopy, since the machined surfaces often exhibits a blurred and rough morphology due to the molten material. Some disagreement at slope angle is also discerned in the cases of $3(\mathrm{~T}) 30^{\circ}$ and $3(\mathrm{~T}) 45^{\circ}$ (Figure 5(b)). Here, height varies from the aimed value because top platform (intact zone) does not exist; hence, it becomes rather difficult to precisely measure such geometrical parameters. It can then be concluded that precision implicit to the production of geometrical features improves as side number as well as side length and slope angles of the shaped pyramids increase.

\subsection{Surface integrity assessment}

Figure 6(a) shows representative patterns of laser-produced pyramids on the cemented carbide studied. From the overall perspective, it can be observed that, for a given side angle, shape contour of the pyramids is better defined when polygon side number increases. Similarly, for a given pyramid shape, contour becomes sharper defined when side angle rises. From the perspective of a single pyramid, it is discerned that covering layer on the pyramid top platform fades away when comparing images from left to right. As a result, platform becomes clear (this being more evident as polygon side 
number increases), and microstructure of the cemented carbide gets revealed. When comparing images from top to bottom, it is observed that as side angle rises, machining quality also improves: polygon sides become straight and top platform gets clean from molten material (uncovered). Following the above ideas and taking into consideration the geometrical measurements, a borderline can be plotted from right-top corner to leftbottom one, below which the laser with proposed machining conditions is capable of yielding shapes of pyramids with targeted geometry.

Figure 6(b) shows a detailed morphological characterization at specific positions: side surfaces and transition zones to the top surfaces. A laminated scale structure forms during the cooling and solidification of the molten material. Solidified layers are rather brittle and overlay each other, containing multiple tiny cracks and pores (Figure 6(c-1)). These scales show very irregular serrated edges and become very rough between laser processed area and intact one (Figure 6(c-2)). At the positions surrounding the pyramids, lamination (scales) disappears and flocculent structures cover the machined surface area. Nevertheless, cracks and pores can still be found on them (Figure 6(c-3)). The cross-sectional inspection at the bottom position is shown in Figure 6(d). A recast layer about $1 \mu \mathrm{m}$ thick with loose and porous structures may be evidenced on top of the bulk-like cemented carbide. Underneath the recast layer, hardmetal microstructure keeps basically unchanged. However, a melting-related transition region (thickness about several ten nanometres) together with some tiny microcracks (length about $100 \mathrm{~nm}$ ) may be discerned (Figure 6(e)). It can be foreseen that the recast layer as a laser ablation aftermath might be harmful because of the implicit surface integrity degradation.

The surface integrity assessment supports the previous discussion regarding geometrical measurements: covering layers associated with molten material may be 
responsible for geometrical deviation, such as height and side length. Since the melting phenomena is proportionally related to applied laser fluence, it is suggested to employ a relatively small laser fluence for the fabrication of more sophisticated profiles, such as triangle and square pyramid with small slope angles, as the melting phenomena is becoming less visible when the dimension decreases. However, the reduction of laser fluence might result in an apparently excessive fabrication time. In this regard, picosecond or femtosecond laser can be used to reduce the melting phenomena as the ultrashort pulse laser is able to avoid the thermal reaction of the materials and reduce the threshold fluence at the same time. Meanwhile, a moderate increase of laser beam overlap is recommended for the acquisition of smoother finished surfaces. However, the overlap should be refrained from certain level, as more melting might be produced by the accumulative energy absorption in the specific volume.

\section{Summary and final remarks}

Pyramid-like patterns with different shapes have been successfully fabricated using a nanosecond laser set-up, and they have shown geometrical features similar to those of abrasive particles on cutting surface of a honing stone.

The measurement of geometrical features proves that high precision has been achieved. However, some deviation is observed and becomes more pronounced when the feature dimension decreases. Surface integrity assessment points out that the molten materials led to such deviation and morphological changes occur in a different way at distinct positions on the pyramid, depending on the dimension of geometric features. It is recommended to use a small laser fluence and large overlap to machine the pyramids for complex profiles, as the melting phenomena can be reduced. 
Further research is recalled to reduce or avoid the occurrence of such solidification-related phenomena. Possible approaches could include adjusting laser parameters, by either lowering pulse energy or shortening pulse duration.

\section{Acknowledgements}

The work received funds from the P.R.I.M.E. project of the German Academic Exchange Service (DAAD) and the Spanish Grant MAT2015-70780-C4-3P (MINECO/FEDER).

\section{References}

[1] Klein, S.; Klein, H.; Bähre, D., Untersuchung des kinematischen Verhaltens beim Präzisionshonen von Bohrungen (Investigation of the kinematic behaviour during precision honing of bores). Jahrb. Schleifen, Honen, Läppen und Polier. Vulkan Verlag. 2019.

[2] Klocke, F. Fertigungsverfahren 2: Zerspanung Mit Geometrisch Unbestimmter Schneide (Manufacturing Processes 2; Machining with geometrically indefinite cutting edges); Springer: Berlin 2017. https://doi.org/10.1007/978-3-662-533109.

[3] Marinescu, I.; Rowe, B.; Dimitrov, B.; Inasaki, I. Tribology of Abrasive Machining Processes. J. Manuf. Sci. Eng. 2004, 126 (4), 859. https://doi.org/10.1115/1.1819313.

[4] Stepien, P. Mechanism of Grinding Wheel Surface Reproduction in Regular Surface Texture Generation. Surf. Eng. 2008, 24 (3), 219-225. https://doi.org/10.1179/174329408X282596.

[5] Zhong, Z. W.; Venkatesh, V. C. Recent Developments in Grinding of Advanced Materials. Int. J. Adv. Manuf. Technol. 2009, 41 (5-6), 468-480. https://doi.org/10.1007/s00170-008-1496-3.

[6] Fang, S.; Llanes, L.; Engstler, M.; Baehre, D.; Soldera, F.; Muecklich, F. Surface Topography Quantification of Super Hard Abrasive Tools by Laser Scanning Microscopy. Mater. Perform. Charact. 2016, 5 (5), 796-815. https://doi.org/10.1520/MPC20160008. 
[7] Takahashi, M.; Ishimura, A.; Aoyama, T.; Inasaki, I.; SATO, J. A Study on Grinding Performance of CBN Grains (2nd Report). J. Japan Soc. Precis. Eng. 2011, 50 (6), 922-925. https://doi.org/10.2493/jjspe1933.50.922.

[8] Arslan, A.; Masjuki, H. H.; Kalam, M. A.; Varman, M.; Mufti, R. A.; Mosarof, M. H.; Khuong, L. S.; Quazi, M. M. Surface Texture Manufacturing Techniques and Tribological Effect of Surface Texturing on Cutting Tool Performance: A Review. Crit. Rev. Solid State Mater. Sci. 2016, 41 (6), 447-481. https://doi.org/10.1080/10408436.2016.1186597.

[9] Fatima, A.; Whitehead, D. J.; Mativenga, P. T. Femtosecond Laser Surface Structuring of Carbide Tooling for Modifying Contact Phenomena. Proc. Inst. Mech. Eng. Part B J. Eng. Manuf. 2014, 228 (11), 1325-1337. https://doi.org/10.1177/0954405413518516.

[10] Fang, S.; Llanes, L.; Bähre, D. Wear Characterization of Cemented Carbides (WC-CoNi) Processed by Laser Surface Texturing under Abrasive Machining Conditions. Lubricants 2017, 5 (3), 20.

https://doi.org/10.3390/lubricants5030020.

[11] Fang, S.; Llanes, L.; Bähre, D. Laser Surface Texturing of a WC-CoNi Cemented Carbide Grade: Surface Topography Design for Honing Application. Tribol. Int. 2018, 122 (2), 236-245. https://doi.org/10.1016/j.triboint.2018.02.018.

[12] Tarragó, J. M. Damage Tolerance of Cemented Carbides under Service-like Conditions Doctor of Philosophy By; 2016.

[13] Dolinšek, S.; Kopač, J. Mechanism and Types of Tool Wear ; Particularities in Advanced Cutting Materials. J. Achiev. Mater. 2006, 19 (1), 11-18.

[14] Dogra, M.; Sharma, V. S.; Dureja, J. Effect of Tool Geometry Variation on Finish Turning - A Review. J. Eng. Sci. Technol. Rev. 2011, 4 (1), 1-13. https://doi.org/10.25103/jestr.041.01.

[15] Yeh, L.-Y.; Hellrung, D.; Gillner, A.; Poprawe, R. Development in the ModelIndustry: Micro-Machining of Hard Metal (WC-10\%Co) by Nd:YAG-Laser. In International Congress on Applications of Lasers \& Electro-Optics; Laser Institute of America, 1999; Vol. 144, pp 144-152. https://doi.org/10.2351/1.5059296.

[16] Hügel H, Graf T. Laser in der Fertigung [Laser in the Production]. Laser der Fert. Wiesbaden: Vieweg+Teubner; 2009. doi: 10.1007/978-3-8348-9570-7.

[17] Bliedtner J, Müller H, Barz A. Laserstrahleigenschaften und -parameter. Lasermaterialbearbeitung [Laser Material Processing]. München: Carl Hanser Verlag GmbH \& Co. KG; 2013. p. 80-109. doi: 10.3139/9783446429291.004.

[18] Dumitru, G.; Lüscher, B.; Krack, M.; Bruneau, S.; Hermann, J.; Gerbig, Y. Laser Processing of Hardmetals: Physical Basics and Applications. Int. J. 
Refract. Met. Hard Mater. 2005, 23 (4-6 SPEC. ISS.), 278-286.

https://doi.org/10.1016/j.ijrmhm.2005.04.020.

[19] Etsion, I. State of the Art in Laser Surface Texturing. J. Tribol. 2005, 127 (1), 248. https://doi.org/10.1115/1.1828070.

[20] Jesudass Thomas, S.; Kalaichelvan, K. Comparative Study of the Effect of Surface Texturing on Cutting Tool in Dry Cutting. Mater. Manuf. Process. 2018, 33 (6), 683-694. https://doi.org/10.1080/10426914.2017.1376070. 


\section{List of Figures}

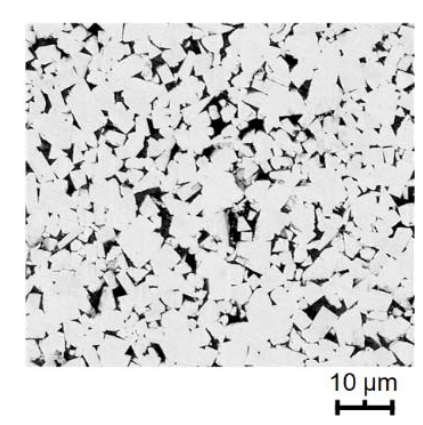

(a)
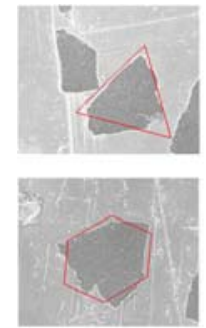

(c)

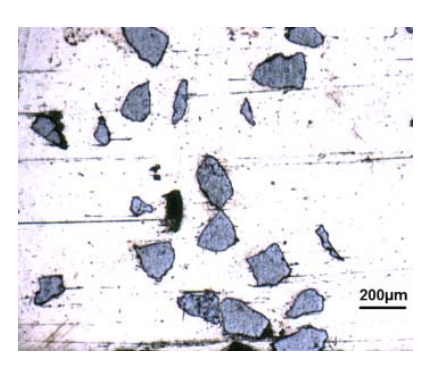

(b)

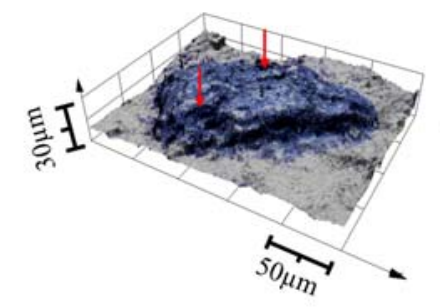

(d)

Figure 1. Microstructural and geometry aspect of (a) $10 \mathrm{CoC}$ hardmetal grade, (b) conventional honing stone, (c) typical grain shapes (triangle, square, hexagon and octagon), and (d) one single abrasive grain.

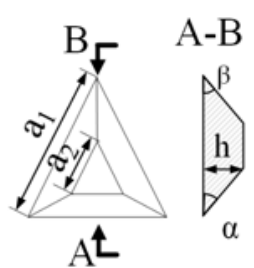

(a)

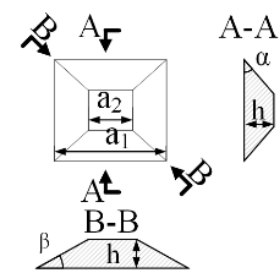

(b)

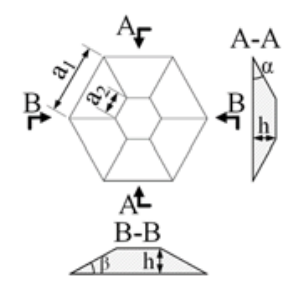

(c)

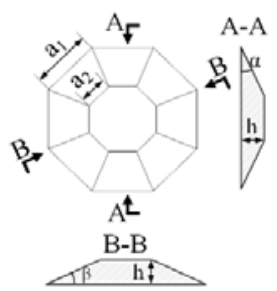

(d)

$a_{1}$ : bottom side length, $a_{2}$ : top side length $h$ : pyramid height, $\alpha$ : slope at the measuring position A-A (side angle), $\beta$ : slope at the measuring position $\mathrm{B}-\mathrm{B}$

Figure 2. Illustration and generic dimensions of pyramid shapes: (a) triangle, (b) square, (c) hexagon, and (d) octagon. 


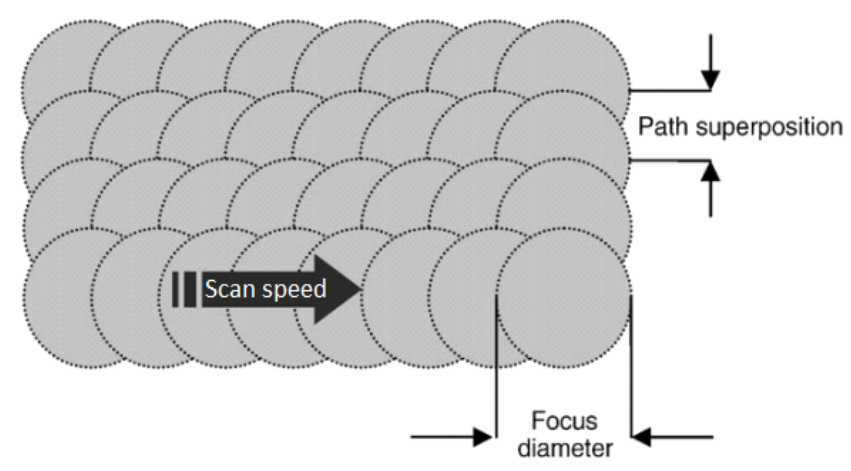

(a)

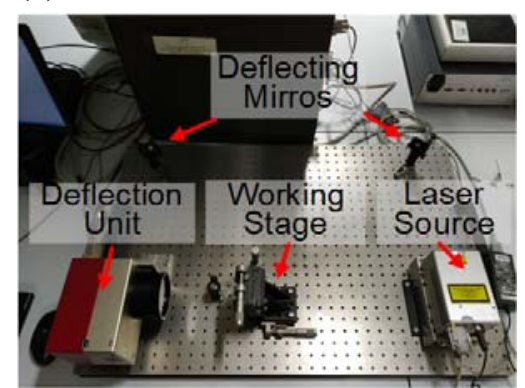

(b)

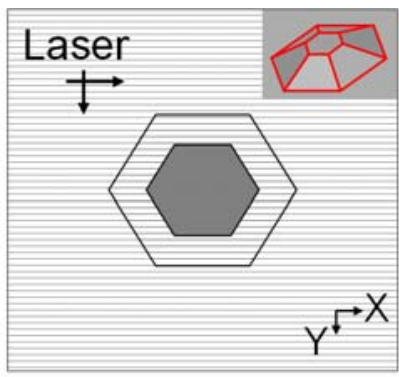

(c)

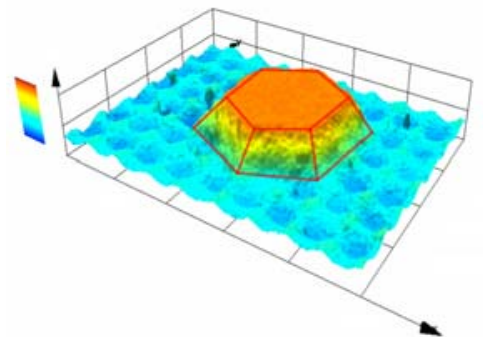

(d)

Figure 3. (a) Schematic illustration of the laser machinig parameters, (b) composition of laser set-up, (c) laser beam path, and (d) reconstructed 3D model based on the dimensional measurements by LSM.

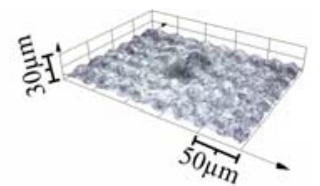

(a)

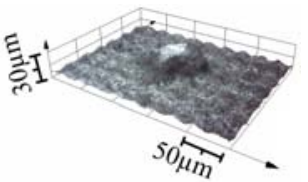

(b)

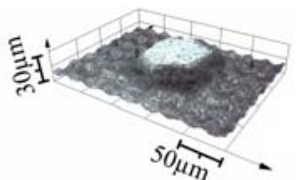

(c)

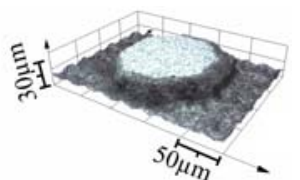

(d)

Figure 4. LSM 3D images of laser-produced pyramids with side angle $45^{\circ}$ : (a) 3(T) triangle pyramid, (b) 4(S) square pyramid, (c) 6(H) hexagon pyramid, and (d) $8(\mathrm{O})$ octagon pyramid. 


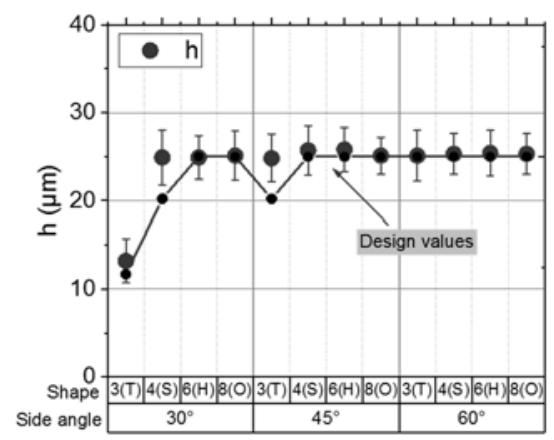

(a)

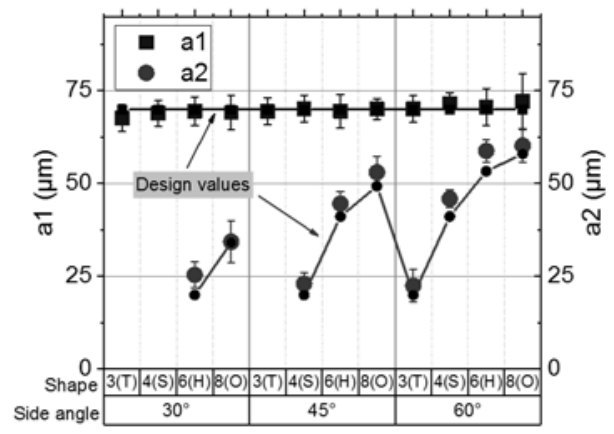

(c)

- $a_{1}$ : bottom side length, $a_{2}$ : top side length $h$ : pyramid height, $\alpha$ : slope at the measuring position A-A (side angle), $\beta$ : slope at the measuring position B-B

- $3(\mathrm{~T})$ - triangle, $4(\mathrm{~S})$ - square, $6(\mathrm{H})$ - hexagon, $8(\mathrm{O})$ - octagon

Figure 5. Comparison of geometrical features between aimed and experimentally attained pyramids: (a) height, (b) side and slope angles, (c) side lengths, and (d) cross-sectional profiles.

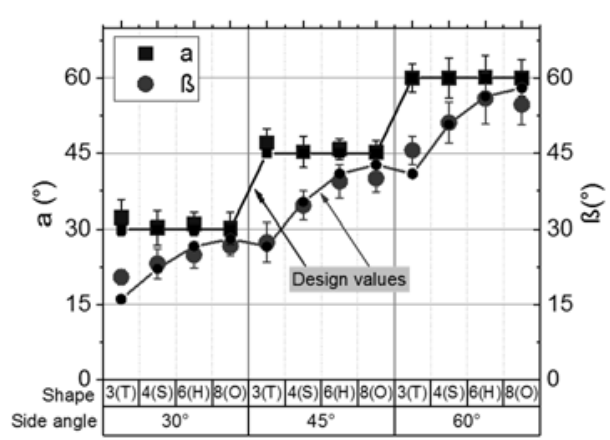

(b)

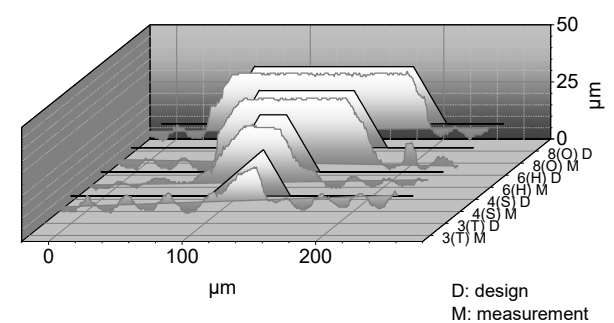

(d) 

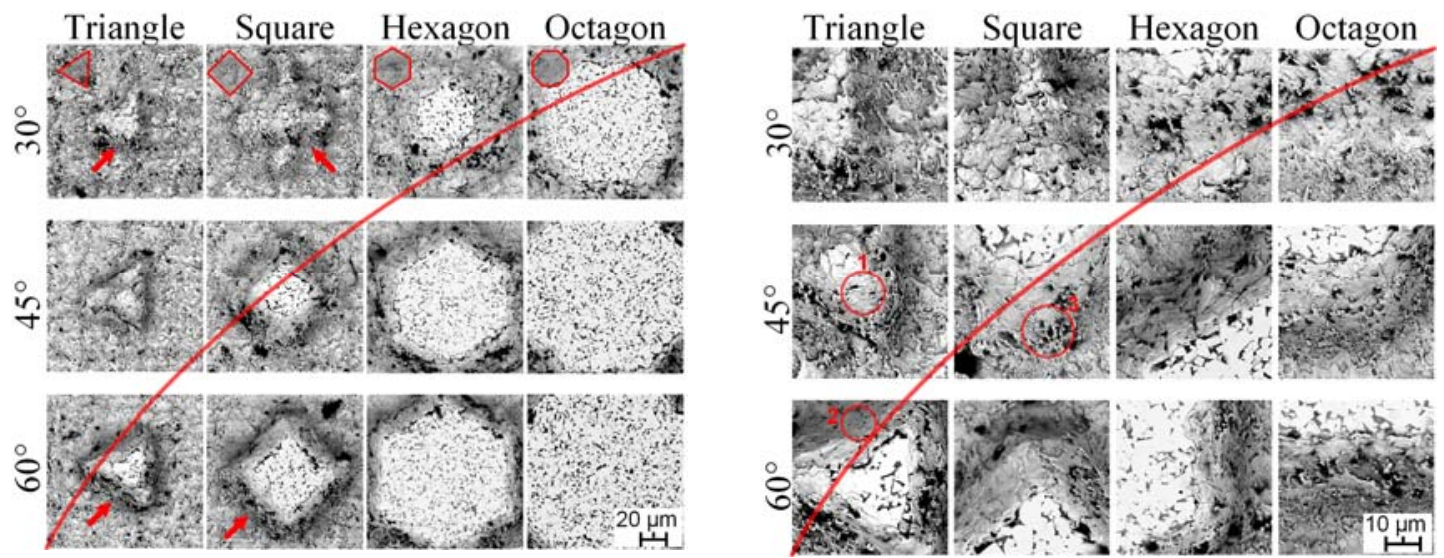

(a)
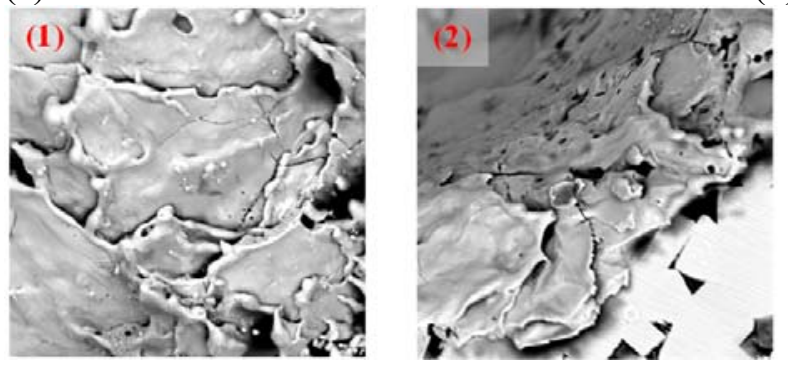

(b)

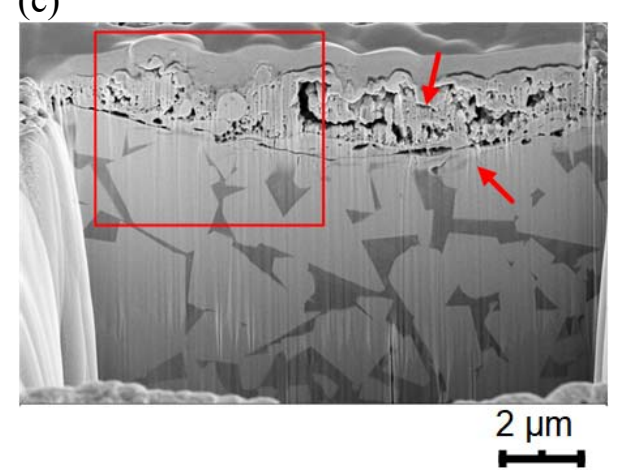

(d)

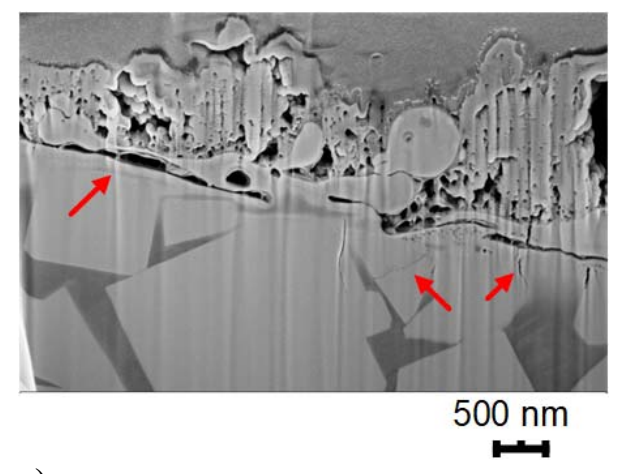

e)

Figure 6. Shape and morphological characterization of single pyramids at (a) large and (b) small scale, (c) high magnification details of selected positions, (d) cross-sectional analysis by FIB at the bottom position, and (e) close-up on the melting zone. 


\section{List of Tables}

Table 1. Aimed and measured geometrical parameters for the designed pyramids.

\begin{tabular}{|c|c|c|c|c|c|c|}
\hline Shape & Parameters & $\alpha\left(^{\circ}\right)$ & $\beta\left(^{\circ}\right)$ & $a_{1}(\mu \mathrm{m})$ & $a_{2}(\mu \mathrm{m})$ & $h(\mu \mathrm{m})$ \\
\hline \multirow{3}{*}{ 点 } & Design & 60 & 40.9 & 70 & 20 & 25 \\
\hline & Measurement & 60 & 45.6 & 70.1 & 22.5 & 25.1 \\
\hline & $\Delta$ & 0 & 4.7 & 0.1 & 2.5 & 0.1 \\
\hline \multirow{6}{*}{ 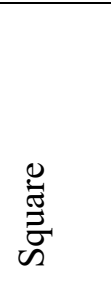 } & Design & 45 & 35.3 & 70 & 20 & 25 \\
\hline & Measurement & 45.3 & 34.6 & 70.2 & 23 & 25.7 \\
\hline & $\Delta$ & 0.3 & -0.7 & 0.2 & 3 & 0.7 \\
\hline & Design & 60 & 50.8 & 70 & 41.1 & 25 \\
\hline & Measurement & 60 & 51.1 & 71.6 & 45.9 & 25.3 \\
\hline & $\Delta$ & 0 & 0.3 & 1.6 & 4.8 & 0.3 \\
\hline \multirow{9}{*}{ 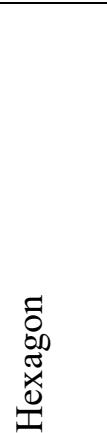 } & Design & 30 & 26.6 & 70 & 20 & 25 \\
\hline & Measurement & 31 & 24.9 & 69.5 & 25.4 & 24.9 \\
\hline & $\Delta$ & 1 & -1.7 & -0.5 & 5.4 & -0.1 \\
\hline & Design & 45 & 40.9 & 70 & 41.1 & 25 \\
\hline & Measurement & 45.8 & 39.4 & 69.5 & 44.6 & 25.8 \\
\hline & $\Delta$ & 0.8 & -1.5 & -0.5 & 3.5 & 0.8 \\
\hline & Design & 60 & 56.3 & 70 & 53.3 & 25 \\
\hline & Measurement & 60.2 & 55.9 & 70.6 & 58.8 & 25.4 \\
\hline & $\Delta$ & 0.2 & -0.4 & 0.6 & 5.5 & 0.4 \\
\hline \multirow{9}{*}{ 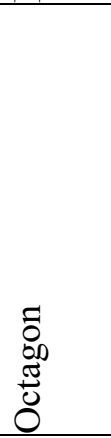 } & Design & 30 & 28.1 & 70 & 34.1 & 25 \\
\hline & Measurement & 30.1 & 26.7 & 69.1 & 34.3 & 25.1 \\
\hline & $\Delta$ & 0.1 & -1.4 & -0.9 & 0.2 & 0.1 \\
\hline & Design & 45 & 42.7 & 70 & 49.3 & 25 \\
\hline & Measurement & 45.2 & 40 & 70.1 & 53 & 25.1 \\
\hline & $\Delta$ & 0.2 & -2.7 & 0.1 & 3.7 & 0.1 \\
\hline & Design & 60 & 58 & 70 & 58 & 25 \\
\hline & Measurement & 60 & 54.7 & 72.1 & 60.2 & 25.3 \\
\hline & $\Delta$ & 0 & -3.3 & 2.1 & 2.2 & 0.3 \\
\hline
\end{tabular}

*not valid for the triangle case $30^{\circ}, 45^{\circ}$ and the square case $30^{\circ}$

Table 2. Parameters of the Nd:YLF Q-switched nanosecond laser unit.

\begin{tabular}{llllll}
\hline $\begin{array}{l}\text { Pulse duration } \\
(\mathrm{ns})\end{array}$ & $\begin{array}{l}\text { Wave length } \\
(\mathrm{nm})\end{array}$ & $\begin{array}{l}\text { Frequency } \\
(\mathrm{Hz})\end{array}$ & $\begin{array}{l}\text { Beam width } \\
(\mathrm{mm})\end{array}$ & $\begin{array}{l}\text { Focus length } \\
(\mathrm{mm})\end{array}$ & $\begin{array}{l}\text { Pulse energy } \\
(\mu \mathrm{J})\end{array}$ \\
\hline 5 & 349 & 1000 & 4 & 136 & 90 \\
\hline $\begin{array}{l}\text { Spot size } \\
(\mu \mathrm{m})\end{array}$ & $\begin{array}{l}\text { Scan speed } \\
(\mu \mathrm{m} / \mathrm{ms})\end{array}$ & $\begin{array}{l}\text { Scan } \\
\text { trajectory }\end{array}$ & $\begin{array}{l}\text { Fill spacing } \\
(\mu \mathrm{m})\end{array}$ & Path number & Spot overlap \\
\hline 19.6 & 8.4 & Line by line & 6 & 12 & $\begin{array}{l}43 \%(8.4 \\
\mu \mathrm{m})\end{array}$ \\
\hline
\end{tabular}

